\title{
O município de Assis Chateaubriand: 48 anos de dinâmica espaço-temporal (1970 - 2018)
}

\section{The municipality of Assis Chateaubriand: 48 years of space- temporal dynamics (1970 - 2018)}

Luciana Virginia Mario Bernardo - Doutora em Desenvolvimento Regional (PGDRA) pela Universidade Estadual do Oeste do Paraná (Unioeste). Professora no curso de Ciências Contábeis na Universidade Federal da Grande Dourados (UFGD). E-mail: lucianavbernardo@ufgd.edu.br

Ricardo Rippel - Doutor em Demografia pela Universidade Estadual de Campinas (Unicamp). Professor no Programa de Pós-Graduação em Desenvolvimento Regional e Agronegócios na Universidade Estadual do Oeste do Paraná (Unioeste). E-mail: ricardorippel@yahoo.com.br

Maycon Jorge Ulisses Saraiva Farinha - Doutorando em Geografia pela Universidade Federal da Grande Dourados (UFGD). E-mail: maycondds@hotmail.com

\section{Resumo}

O objetivo do estudo foi analisar as alterações populacionais e fundiárias a partir da década de 1970 e o uso da terra na atualidade do município de Assis Chateaubriand. O recorte temporal está relacionado à disponibilidade de informações oriundas do Instituto Brasileiro de Geografia e Estatística e MapBiomas. Foi realizada a triangulação de dados, sendo este um procedimento que concilia diferentes maneiras para a coleta de dados sobre uma determinada situação, problema ou amostra. Os resultados identificados apontam que o município sofreu alterações significativas na substituição da vegetação natural por alguns usos intencionais da terra, com predominância, desde o início da década de 1970, dos usos relacionados à agropecuária, com ênfase na agricultura.

\section{Palavras-chave}

Uso da Terra. Modernização Agrícola. Colonização. Produção Rural.

\section{Abstract}

The objective of the study was to analyze the population and land changes since the 1970 s and the use of land today in the municipality of Assis Chateaubriand. The time frame is related to the availability of information from the Brazilian Institute of Geography and Statistics and MapBiomas. Data triangulation was performed, which is a procedure that reconciles different ways to collect data about a given situation, problem or sample. The results identified indicate that the municipality has undergone significant changes in the replacement of natural vegetation by some intentional land uses, with predominance, since the beginning of the 1970s, of uses related to agriculture, with emphasis on agriculture.

\section{Keywords}

Land Use. Agricultural Modernization. Colonization. Rural Production. 


\section{INTRODUÇÃO}

O município de Assis Chateaubriand está localizado na Região Oeste do Paraná, tendo sido criado em 1966 a partir do seu desmembramento do município de Toledo. Para Lima (2004), o projeto urbanístico do distrito sede municipal está associado a negociações agrícolas e imobiliárias. A atração das pessoas para o município, a partir da década de 1960, ocorreu pela esperança de adquirir terras que possibilitasse a melhoria da qualidade de vida da família a partir da produção rural. Havia ali, contudo, uma realidade prévia. Assim, ao mesmo tempo em que o município recebia essas pessoas vindas de diferentes partes do Brasil ocorria ali um processo de expulsão demográfica, realizado, muitas vezes, mediante o uso da força, principalmente com aqueles que habitavam o local anteriormente à instalação da empresa colonizadora Norte do Paraná. Foi desse modo que, na história do município, especialmente na época da sua colonização, foi sendo criado um cenário demográfico complexo, deixando, assim, uma marca na história local que, embora tenha sido um panorama de conflitos e de violência, no cotidiano é pouco lembrada (CRESTANI, 2011; RIPPEL, 2005).

Essa colonização foi realizada, no início deste processo, pela primeira corrente migratória que chegou ao município, originária da região Norte do país. Ela foi constituída de nordestinos e de mineiros que já haviam participado da colonização da região Norte do estado do Paraná. Essas pessoas trouxeram com eles a cultura agrícola cafeeira para a região. A segunda corrente migratória que chegou ao município foi intitulada como sulista. Os sulistas traziam o costume de produzir lavouras brancas, como milho e feijão, bem como introduziram a produção animal no local (SOUTO MAIOR, 1996). Cabe indicar que tanto os cultivos de cafezais como os de milho e feijão, demandavam um número significativo de trabalhadores rurais, pois eram empreendidos manualmente (RIPPEL, 2005).

Assim, nesse período inicial de colonização do município, a principal atividade econômica era primária, com predominância agrícola com grande uso de mão de obra, devido à baixa mecanização da produção. Foi essa característica que, inicialmente, possibilitou que as pessoas que chegassem ao município pudessem ser alocadas no espaço rural e ter renda para ali se manterem. Ademais, o processo de formação do município propiciou a alteração da paisagem natural na área a partir da intervenção humana no meio ambiente orientada pelos objetivos que a sociedade local do período estabeleceu. Nesse movimento, vê-se que a vegetação densa, característica do bioma Mata Atlântica, foi suprimida e substituída a partir da ocupação humana e da produção econômica desenvolvida em ciclos relacionados à produção rural. 
Isso resultou, com o passar dos anos, em áreas de vegetação natural cada vez menores em razão da expansão das paisagens de produção agropecuária e urbanização, sendo que essas características da produção econômica e social do município se estabeleceram e têm perdurado no decorrer dos anos. Santos e Ferrera de Lima (2015) indicam que na atualidade, a economia do município tem baixa participação da indústria, ou seja, de uma economia urbana, com um perfil de desenvolvimento local que necessita de avanços para a geração de emprego e renda. Essas características são descritas pela paisagem que pode ser observada no decorrer dos anos, pelo registro de imagens, pelos elementos que ainda estão visíveis no município e ainda, pela quantificação do uso da terra, realizada pelas instituições.

Desse modo, o cenário apresentado para o município inspira a seguinte indagação: que alterações ocorreram com a ocupação do solo e da paisagem do município de Assis Chateaubriand no decorrer de sua história? O questionamento se justifica a partir das características de colonização do município com finalidades agropecuárias com estrutura fundiária direcionada para pequenas propriedades. Denota-se que as atividades rurais, ainda se mantêm na atualidade, contudo, com uma estrutura fundiária diversificada e ainda, mais direcionada a produção agrícola tecnificada, formato este muito comum em diferentes localidades brasileiras. Essa característica possibilita a redução da oferta de empregos no rural e exige a inserção de capital para o financiamento desse formato produtivo.

Além disso, a história do município indica um rápido processo de atração da população para a localidade no decorrer de sua colonização, motivada pela possibilidade de melhorias na qualidade de vida. Essa população está predominantemente localizada no espaço rural, atuando como proprietários e trabalhadores rurais. Contudo, destaca-se a falta de diversificação das atividades econômicas municipais e as dificuldades em continuar com as práticas rurais em pequenas propriedades. Essas dificuldades são devido à ausência de incentivo públicos para as culturas produzidas na época e exigências de investimento de capital para a produção de novas culturas que atendiam a necessidade do mercado, o município não conseguiu evitar um rápido processo de emigração. Assim, a história do município está relacionada a questões vinculadas ao uso da terra e a demografia. Dessa forma, o objetivo geral do estudo foi analisar as alterações populacionais e fundiárias a partir da década de 1970 e o uso da terra na atualidade do município de Assis Chateaubriand, no Paraná. O recorte temporal está relacionado à disponibilidade de informações dos censos disponibilizados pelo Instituto Brasileiro de Geografia e Estatística (IBGE) e pelo MapBiomas. 
A estrutura deste artigo encontra-se organizada a partir desta introdução que contextualiza características do município investigado. Na sequência, abordouse os materiais e métodos utilizados, posteriormente os resultados e discussão foram identificados e, por fim, as considerações finais sobre o estudo realizado.

\section{MATERIAIS E MÉTODO}

\subsection{LOCALIZAÇÃO DO MUNICÍPIO}

Pode-se observar que o município está localizado na região Oeste do Paraná (Figura 1). A estimativa de sua população, segundo IBGE (2020), é de 33.362 habitantes em 2019, com densidade demográfica de 34,06 habitantes por quilômetros quadrados. Seu Índice de Desenvolvimento Humano Municipal é de 0,729 . O percentual de arborização de vias públicas é de $91,3 \%$, com características da vegetação do bioma Mata Atlântica.

Figura 1 - Localização do município de Assis Chateaubriand - Paraná

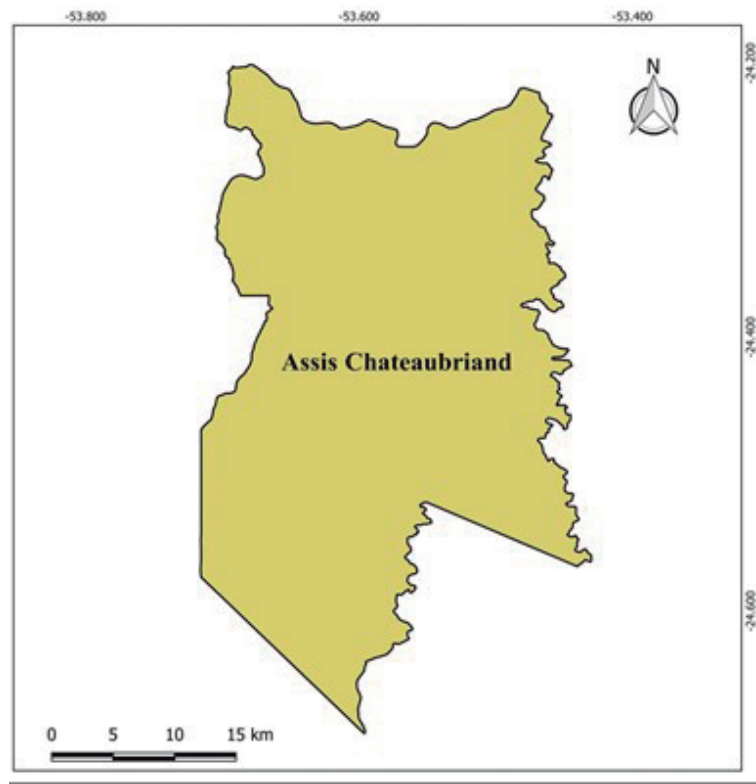

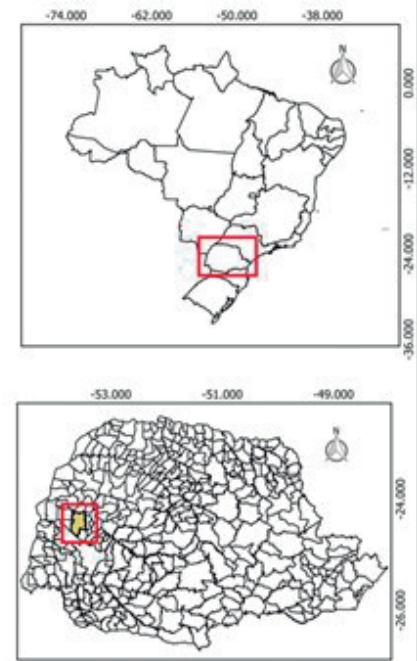

Projeção UTM, DATUM: SIRGAS 2000, Fonte: IBGE (2015).

\subsection{COLETA E USO DAS INFORMAÇÕES SOBRE O MUNICÍPIO}

Foi realizada a triangulação de dados, sendo este um procedimento que concilia diferentes maneiras para a coleta de dados sobre uma determinada situação, 
problema ou amostra. Dessa forma, a primeira etapa da triangulação consiste na coleta de fotografias disponibilizadas no acervo da biblioteca municipal de Assis Chateaubriand. As imagens auxiliarão a representar as características iniciais do município. A segunda etapa consiste na coleta de imagens de satélite do município, ao qual indicarão as características da atualidade. Considerando que o ferramental imagético (imagens) é um importante meio de comunicação, o uso de fotografias que representam um dado momento no tempo, pode ser considerado um registro do mesmo (RODRIGUES, 2007). Dessa forma, realizando uma análise imagética, pretende-se responder ao máximo de questionamentos apontados por Panofsky (1979), Manini (2001) e Maiomone e Gracioso (2007) e exemplificados por Manini (2001), sendo eles:

Quem ou o que aparece na imagem (descrição ou nome das pessoas e/ou lugares); Que lugar aparece na imagem (localização espacial e geográfica); Quando foi realizada a tomada (indicação de data, tempo cronológico ou ocasião); Como são ou estão os principais elementos da imagem (complementação da descrição inicial feita do motivo principal da imagem); O que indica esta imagem (de que ela é o traço, a marca, o sinal). As respostas a estas perguntas devem ser dadas com base em informações concretas provenientes da imagem ou de seu referente (MANINI, 2001, p. 4, grifos nossos).

Considerando a importância do território rural para o município, a terceira etapa da triangulação consiste em caracterizar a estrutura desse espaço. Para isso, foi realizada uma coleta de dados a partir da década de 1970 até os dias atuais. O estabelecimento desse período esteve relacionado à disponibilidade de dados, tendo em vista que a área de estudo foi considerada município em 1966. As variáveis utilizadas foram (i) uso da terra, (ii) produção rural, (iii) estrutura fundiária e (iv) informações populacionais, sendo esta última variável, contemplando o município como um todo. As informações foram coletadas nos Censos Agropecuário e Demográfico do IBGE, estando disponibilizadas em respectiva plataforma on-line e documentos impressos. Ademais, no que se refere às mudanças no uso da terra, o período de análise compreendeu o ano de 1985 a 2017, a partir de informações geradas pela MapBiomas (2019). É uma iniciativa multi-institucional, constituída por universidades, ONGs e empresas de tecnologia que disponibilizam uma plataforma de dados on-line, referente ao uso da terra.

A triangulação, para Flick (2009a, 2009b, 2013), refere-se à combinação de diferentes características como métodos qualitativos e quantitativos, período de tempo, diferentes fontes de dados entre outros. Assim, neste estudo, observa-se que a triangulação foi realizada a partir da análise de diferentes períodos de tempo 
(1970 a 2017), com origem em diferentes fontes como citadas anteriormente e pelo uso de diferentes métodos a análise de imagens e estatística descritiva.

\section{RESULTADOS E DISCUSSÃO}

A Figura 2 apresenta uma vista aérea do município de Assis Chateaubriand, em 1961, de autor desconhecido, fotografia confeccionada em preto e branco. Observa-se que mesmo esta imagem não corresponder ao período temporal da análise proposta sobre o município, considerou-se que a mesma deveria ser utilizada, devido a sua importância para demonstrar a paisagem que havia na localidade. A fotografia, na pesquisa, foi considerada a representação inicial da formação do município. Assim, nota-se a urbanização inicial do município a partir da derrubada da vegetação natural e substituição por ruas e construções. Pode-se observar ainda, que a clareira aberta na mata densa é ocupada por um número pequeno de construções características da área urbana de uma localidade. Além disso, nos extremos da clareira podem ser identificadas áreas em que a mata já havia sido retirada e ainda não havia sido substituída, ou seja, áreas expostas aguardando seu novo uso. Observa-se, ainda, para além da clareira, a vegetação natural referente ao bioma Mata Atlântica, característico da região e ainda não substituído no momento da fotografia.

Figura 2 - Transformações do Município de Assis Chateaubriand, 1961

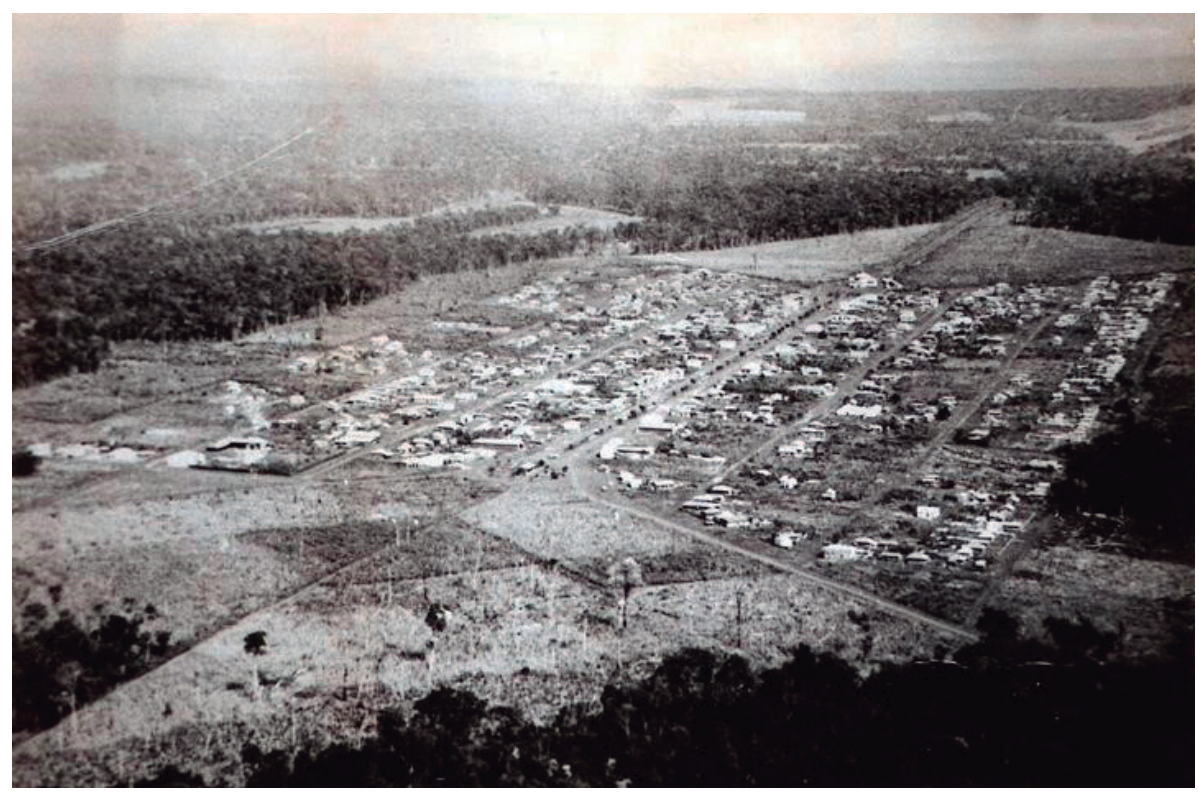

Fonte: Acervo da biblioteca municipal de Assis Chateaubriand (1961). 
A Figura 3 refere-se ao ano de 2018 é colorida e foi coletada por meio do uso de geotecnologias, disponibilizada pelo Google Earth Pro. A imagem mostra uma maior abrangência sobre a área do município. Essa maior abrangência foi possível devido ao desenvolvimento tecnológico ocorrido na área das geotecnologias, que têm proporcionado aumento na qualidade de informações via imagem de satélite. Além disso, é possível observar, com a imagem, a indicação da substituição da maioria da vegetação natural do município na proporção territorial captada pela imagem, por área rural e urbana, com predominância rural. A vegetação natural remanescente em área urbana é a denominada área de conservação "Parque Ecológico São Francisco de Assis", criado em 1978, também conhecido popularmente como "horto". Essa área totaliza $496.100 \mathrm{~m}^{2}$ e é utilizada como lazer pelos residentes do município de Assis Chateaubriand.

A imagem de 2018 proporciona a visibilidade da paisagem alternada, característica do processo produtivo agrícola e urbano. Ela mostra o encerramento de um ciclo produtivo dentro da propriedade rural, de forma que o solo está exposto, aguardando novo plantio ou o crescimento da vegetação. Poderia haver outros motivos para que o solo estivesse exposto como mineração ou degradação de terra, porém, não foram identificados estudos que revelem essas características para o município. Além disso, o mês da imagem corresponde ao período de colheita da produção. Por isso, se justifica a exposição do solo com o encerramento de um ciclo produtivo dentro da porteira.

Figura 3 - Transformações do Município de Assis Chateaubriand, Ano 2018

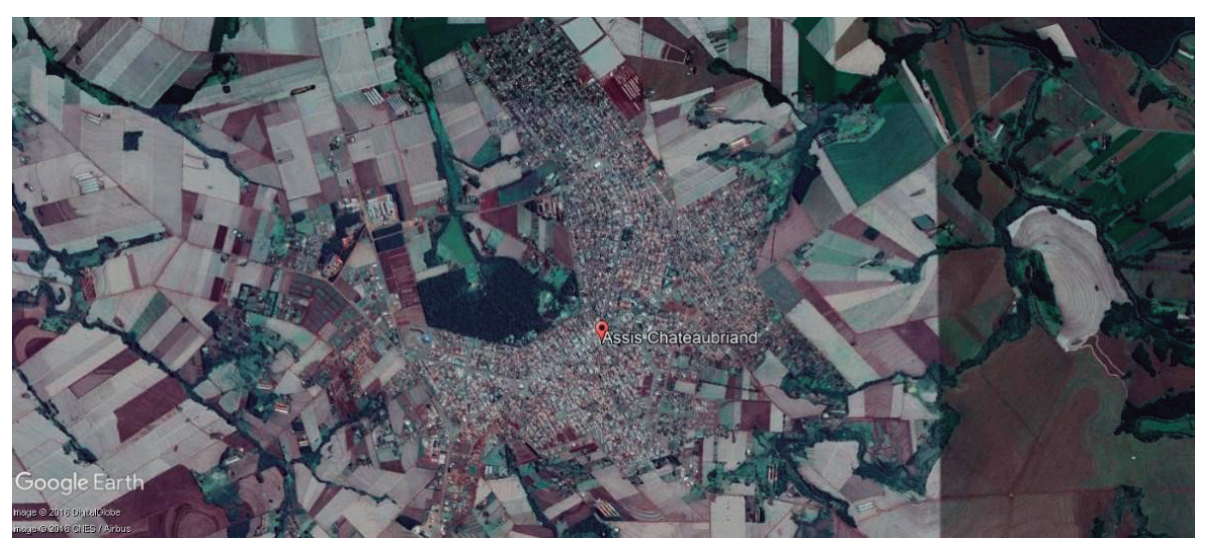

Fonte: Google Earth Pro (2018).

Neste movimento de análise, também fez-se o uso do Ipardes (2019), que disponibiliza informações sobre o Grau de Urbanização dos municípios paranaenses, para anos próximos aos das imagens, que auxiliam na verificação do aumento da 
população urbana no município. Assim, o Grau de Urbanização é o resultado da relação (\%) entre a população urbana e a população total de uma localidade. Em 1980, o Grau de urbanização para o município de Assis Chateaubriand era de 52\%, aumentado para 86\% em 2007 e para 88\% em 2010. Infelizmente, não há informações censitárias anteriores a 1980 ou posteriores a 2010.

Swain (1992) considera que a criação do município esteve relacionada à expansão da fronteira agrícola da Região Oeste do Paraná, ocorrida na década de 1950, com o intuito de auxiliar o suprimento da demanda alimentar da Região Sudeste do país. Dessa forma, o projeto urbanístico do município, para Lima (2004), está associado a negociações agrícolas e imobiliárias. Além disso, Marques (2017) observa que essa colonização esteve vinculada a um conjunto de interesses por parte dos diferentes agentes que compuseram o cenário. No que se refere à colonizadora, essa empresa estava focada nos lucros gerados com a comercialização das terras. Quanto ao estado do Paraná, devido ao fato de a área municipal estar no raio de ação da fronteira Brasil-Paraguai, interessava reforçar o desenvolvimento da política de povoamento e segurança. E, quanto à população atraída ao território, de diversificada procedência, a esperança de melhoria das condições de vida.

Em relação a essa esperança de melhorias, a Figura 4 reforça a ideia apresentada por Boritza (2011), que indica que houve uma propaganda intencional dos promotores iniciais do município para atração das pessoas para uma localidade que criava expectativas de progresso. A imagem ilustra a Avenida Tupãssi, área central do município na década de 1960, de autor desconhecido. Observa-se que não havia asfaltamento na época, que só ocorreu posteriormente, em meados da década de 1970. Na placa, o município de Assis Chateaubriand foi considerado a "capital do progresso" e se fazia um convite para que as pessoas de fora o conhecessem. A mensagem induz à crença de que os indivíduos que residiam no local eram beneficiados pelos resultados oriundos do progresso que estava acontecendo.

Posteriormente, contudo, mesmo com o uso do slogan "Capital do Progresso" e o deslocamento das pessoas para o município, como demonstrou Souto Maior (1996), esses fatores não garantiram a permanência de todos os que ali chegaram, como apontado também por Rippel (2005). De tal modo que outro slogan poderia ter sido utilizado para o município no decorrer de sua história, "Capital da Promessa", devido alguns mitos criados no local, sobre a atração de empresas ou instituições que poderiam ter contribuído para que houvesse um maior desenvolvimento do município. Contudo, estas estavam destinadas a outras localidades, ou como Souto Maior (1996) relata, foram implantadas no município, inicialmente anunciadas como algo próspero, mas a história demonstra que não trouxeram os resultados esperados. 
Figura 4 - "Capital do Progresso" - Assis Chateaubriand na década de 1960

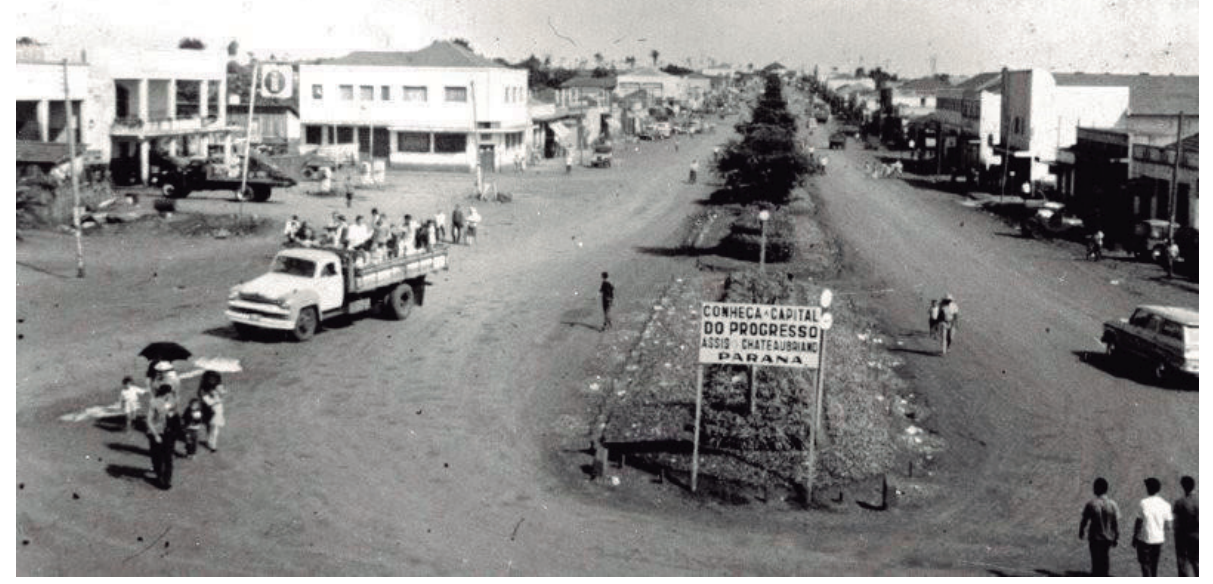

Fonte: Acervo da biblioteca municipal de Assis Chateaubriand (2018).

Quanto à população chateaubriandense, pode ser identificada a sua variação no decorrer dos anos, sendo que, quando negativa, indica que houve insucessos na permanência das pessoas no local, de maneira que parte dos indivíduos migrou para outras localidades. Observa-se que os registros realizados pelos Censos Demográficos revelam que a população do município foi reduzida a cada pesquisa realizada no período de 1970 a 2010, tendo essas reduções sido de 30,5\% entre 1970 e 1980 , de 27,3\% entre 1980 e 1991, de 16\% entre 1991 e 2000 e de $0,9 \%$ entre 2000 e 2010 (Tabela 1).

Comparando o primeiro com o último ano (1970 e 2010), a redução da população foi de 58\%, uma vez que em 1970, o município possuía um total de 78.600 pessoas e em 2010 esse número foi reduzido para 33.025. Outro aspecto que pode ser verificado são os percentuais entre a população masculina e feminina no município, tanto no espaço urbano quanto no rural. Por fim, observa-se que, no município, apenas na década de 1970 a população rural era predominante no município (86\%) e em 2010, houve inversão, tornando o urbano com a maior concentração populacional (88\%). Isso novamente se refere ao Grau de urbanização, conforme disponibilizado pelo Ipardes (2019), para demonstrar o adensamento populacional do município na área urbana em período de tempo maior, iniciado em 1980 com 52\%, alterado para 73\% em 1991, ampliado para $81 \%$ em 2000 e aumentado para 88\% em 2010. 
Tabela 1 - Residentes no município de Assis Chateaubriand, por sexo e situação do domicílio - 1970 a 2010

\begin{tabular}{|c|c|c|c|c|c|c|c|c|c|}
\hline & \multicolumn{3}{|c|}{1970} & \multicolumn{3}{|c|}{1980} & \multicolumn{3}{|c|}{1991} \\
\hline & 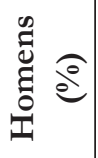 & 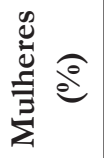 & 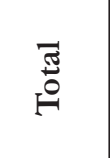 & 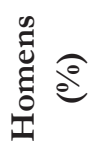 & 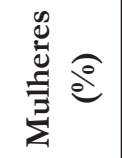 & : & 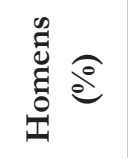 & 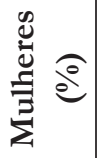 & \\
\hline Total & 52 & 48 & 78.600 & 51 & 49 & 54.629 & 50 & 50 & 39.737 \\
\hline Urbana & 51 & 49 & 11.239 & 50 & 50 & 28.379 & 49 & 51 & 28.835 \\
\hline \multirow[t]{3}{*}{ Rural } & 53 & 47 & 67.361 & 52 & 48 & 26.250 & 52 & 48 & 10.902 \\
\hline & \multicolumn{3}{|c|}{2000} & \multicolumn{3}{|c|}{2010} & \multicolumn{3}{|c|}{$\begin{array}{c}\text { Variação População } \\
\text { Total - } 1970 \text { e } 2010(\%)\end{array}$} \\
\hline & 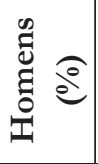 & 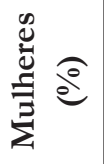 & 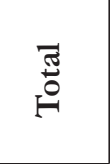 & 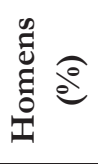 & 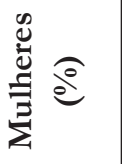 & 褐 & 褐 & 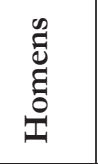 & 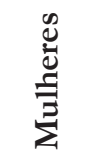 \\
\hline Total & 49 & 51 & 33317 & 49 & 51 & 33025 & -58 & -61 & -55 \\
\hline Urbana & 49 & 51 & 27.052 & 49 & 51 & 29.013 & 158 & 149 & 168 \\
\hline Rural & 51 & 49 & 6.265 & 51 & 49 & 4.012 & -94 & -94 & -94 \\
\hline
\end{tabular}

Fonte: Elaborado a partir do IBGE (1970a, 1980, 1991, 2000, 2010).

Após verificar os dados sobre a população do município, outras informações puderam ser identificadas. Dentre as informações disponíveis está o uso da terra. A Figura 5 traz as informações referentes a essa organização no período de 1985 a 2017. Foi estimado o percentual de participação das categorias de uso da terra: i) floresta, ii) agropecuária, iii) área não vegetada e iv) corpo d'água, sendo essas as categorias tradicionais de análise de uso da terra na Geografia. Pode-se observar que a categoria de uso da terra identificada como Agropecuária é aquela que ocupou, em todos os anos de análise, o maior número de hectares de terra disponíveis no município.

Destaca-se que as categorias de uso da terra podem ser distribuídas em subcategorias, de forma a oferecer informações mais detalhadas sobre cada categoria. A primeira categoria é Floresta, que, em Assis Chateaubriand, nos anos de 1985 e 1995, foi constituída exclusivamente por Floresta Natural, ou seja, formação vegetal natural. Em 2005, essa composição já se encontrava alterada, pois $0,34 \%$ dos hectares referentes à categoria Floresta estavam ocupados por Florestas Plantadas, sendo que, em levantamento recente, em 2017, esse percentual aumentou para 7,3\%, indicando a permanência e a ampliação dessa produção rural. Cabe aqui mencionar que florestas plantadas são aquelas produzidas com a finalidade comercial, como, por exemplo, as de eucalipto (MAPBIOMAS, 2019). 
Figura 5 - Uso da terra do município de Assis Chateaubriand, em Percentual 1985 a 2017

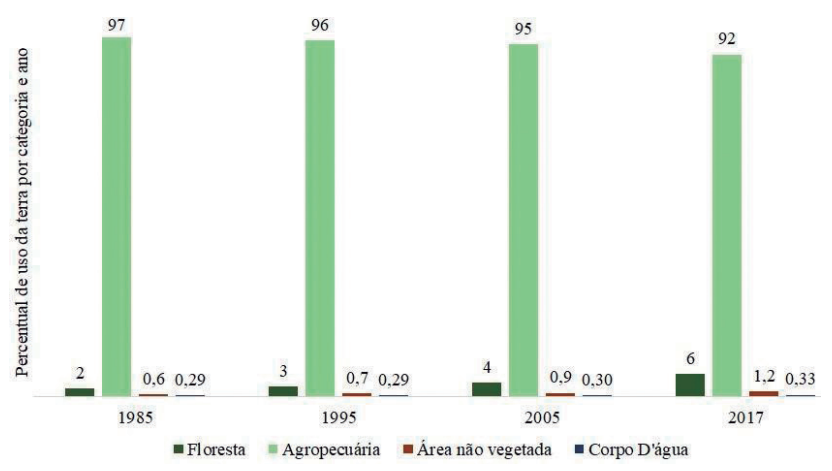

Fonte: Elaborado a partir de MapBiomas (2019).

A segunda categoria de análise é a Agropecuária, que pode ser distribuída em três subcategorias, quais sejam: a) pastagem, b) agricultura e c) mosaico de agricultura ou pastagem - observando-se que esta última subcategoria contém as áreas em que não foi possível distinguir se eram áreas de pastagem ou agrícolas (MAPBIOMAS, 2019). Mediante os resultados identificados com o uso da terra de Assis Chateaubriand, a partir de suas características, considerando a relevância da categoria Agropecuária para o município, optou-se por detalhá-la a partir de suas subcategorias.

Entre as subcategorias que compõem a categoria Agropecuária, destacase a Agricultura, que ocupa o maior percentual de hectares da categoria (Figura 6). $\mathrm{O}$ valor identificado nos anos analisados nunca foi inferior a $88 \%$, sendo esse considerado um valor expressivo, indicando a relevância desse uso da terra para o município e, ainda, a manutenção desse perfil no decorrer dos anos. Além disso, observa-se que a subcategoria Pastagem tem sido reduzida no decorrer do tempo, passando de 7\% em 1985 para 1\% em 2017. E no caso do mosaico observa-se uma variação no decorrer dos anos.

Figura 6 - Percentual de uso da terra do município de Assis Chateaubriand, por subcategorias da Agropecuária - 1985 a 2017

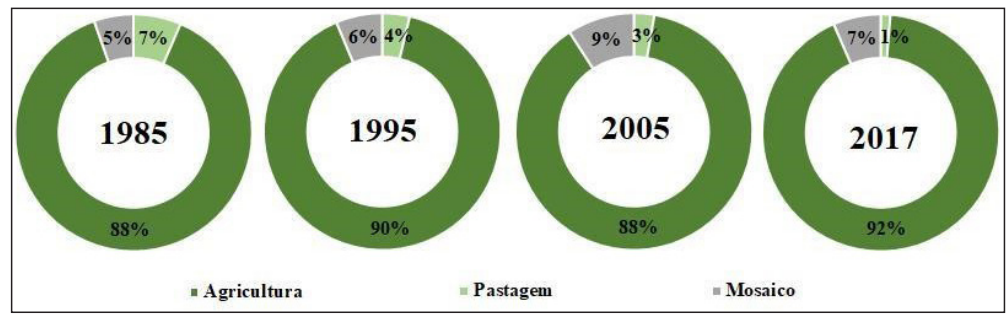

Fonte: Elaborado pelo autor a partir MapBiomas (2019). 
Dando continuidade à análise das categorias utilizadas para identificar o uso da terra do município no decorrer dos anos, a próxima categoria é a área não vegetada. Esse agrupamento de uso da terra do município é formado, desde 1985, pelas subcategorias Infraestrutura Urbana e Outra Área Não Vegetada. Esta última subcategoria, para o MapBiomas (2019), no bioma Mata Atlântica, é formada por áreas de superfícies não permeáveis que não puderam ser classificadas nem infraestrutura urbana nem em mineração. Ocorre que essa categoria de análise tem aumentado no decorrer dos anos, entre 1985 e 2017, pois há um crescimento de $124,5 \%$ no uso da terra. A predominância de classificação nas subcategorias identificadas refere-se à infraestrutura urbana, superior a $85 \%$, em todos os anos de análise.

E, por último, a categoria Corpo d'Água, está relacionada a todo tipo de recurso hídrico, porém, em Assis especifica-se a local com água doce. Os registros denotam que há um aumento de 15\% no número de hectares de recursos hídricos identificados entre 1985 e 2017. Esse aumento está relacionado a ações governamentais de incentivo à preservação de mata ciliar nos rios e à conservação de nascentes, tendo em vista que o estado tem uma trajetória de incentivos a implantação de políticas públicas ambientais, como o caso do pagamento, por serviços ambientais (NASCIMENTO et al., 2011).

Depreende-se que deve ser considerado que a terra é um recurso natural utilizado em diferentes atividades humanas e, por isso, é reconhecida a sua importância (BAJA et al., 2002; BESTELMEYER et al., 2004). Dessa forma, medidas devem ser utilizadas para reduzir as possibilidades de haver problemas com esse recurso, como para reduzir a degradação e processos erosivos que possam inviabilizar seu uso (ZHANG; YUE; FANG, 2018). No caso de Assis Chateaubriand, foi identificado um uso da terra direcionado, em sua maioria, para atividades agrícolas e, dessa forma, é exigida, segundo Anderson Serra (2005), a utilização de manejos específicos para as características produtivas. Essa medida pode ser eficiente na redução do empobrecimento do solo ao final de ciclos produtivos, dentre outros problemas que a falta do uso de manejo pode ocasionar.

Observa-se que problemas de comprometimento do solo podem ocorrer em espaços rurais e urbanos. Por isso, identificar as características dos solos antes de realizar seu planejamento de uso, de forma a criar uma seletividade para as áreas, é uma importante medida a ser tomada, seja por gestores, seja por usuários desse recurso natural (CAMPOS et al., 2010; CUNHA; PINTON, 2012). Há que considerar que impactos ambientais no solo, ocasionados por atividades não compatíveis com as suas características, podem resultar em outros aspectos negativos nos demais recursos naturais relacionados, como a contaminação 
de águas subterrâneas (EMBRAPA, 2013). Dessa forma, a sustentabilidade da utilização da terra deve ser considerada como sendo um aspecto influente para as questões econômicas, de provisão alimentar, de conservação ambiental e de desenvolvimento regional de determinada localidade (MERTZ; MERENS, 2017; SPALDING, 2017).

Dentre as produções agropecuárias realizadas no decorrer da história do município, há predominância agrícola referente à produção de culturas temporárias. Essa configuração permaneceu no decorrer dos anos analisados (Tabela 2). O fato mais curioso nessa configuração do espaço rural chateaubriandense está na predominância produtiva de culturas temporárias, de modo a contrariar os ditos populares referentes à predominância da produção cafeeira, com muitas culturas no estado do Paraná até meados da década de 1970, porém, em regiões no nortenoroeste do mapa paranaense.

Tabela 2 - Uso da terra rural do município de Assis Chateaubriand - Paraná 1970 a 2017

\begin{tabular}{l|r|r|r|r|r|r}
\hline \multirow{2}{*}{ Uso da terra rural } & \multicolumn{7}{c}{ Ano/hectares } \\
\cline { 2 - 7 } & $\mathbf{1 . 9 7 0}$ & $\mathbf{1 . 9 7 5}$ & $\mathbf{1 . 9 8 5}$ & $\mathbf{1 . 9 9 5 / 9 6}$ & $\mathbf{2 0 0 6}$ & \multicolumn{2}{c}{$\mathbf{2 0 1 7}$} \\
\hline Permanente & 10.263 & 12.980 & 774 & 385 & 423 & 55 \\
\hline Temporária & 55.024 & 74.194 & 74.260 & 74.182 & 70.109 & 67.684 \\
\hline Pastagem natural & 698 & 2.642 & 188 & 602 & 592 & 1.197 \\
\hline Pastagem plantada & 9.008 & 9.010 & 8.217 & 8.959 & 4.536 & 1.315 \\
\hline Matas e florestas naturais & 9.678 & 2.724 & 1.218 & 2.437 & 7.359 & 6.464 \\
\hline Matas e florestas plantadas & 105 & 103 & 696 & 994 & 69 & 254 \\
\hline Terras produtivas não utilizadas & 1.671 & 2.143 & 1.183 & 527 & 0 & 0 \\
\hline Total & $\mathbf{8 6 . 4 4 7}$ & $\mathbf{1 0 3 . 7 9 6}$ & $\mathbf{8 6 . 5 3 6}$ & $\mathbf{8 8 . 0 8 6}$ & $\mathbf{8 3 . 0 8 8}$ & $\mathbf{7 6 . 9 6 9}$ \\
\hline
\end{tabular}

Fonte: Elaborado a partir do IBGE (1970b, 1975, 1985, 1996, 2006, 2017).

$\mathrm{Na}$ hipótese de ter havido no município uma produção cafeeira maior, ou seja, em áreas produtivas maiores, essa produção provavelmente já tinha sido substituída por outra cultura agrícola antes mesmo da geada negra de 1975. O que se depreende dessas substituições é que houve sucessivas geadas anuais a partir de 1953 (SERRA, E., 2010) e que podem ter sido a motivação principal para a mudança produtiva. Essa constatação fica mais evidente quando se observam os registros do Censo Agropecuário de 1970 (IBGE, 1970b). Em relação ao valor da produção do respectivo ano, foi identificado que o setor rural chateaubriandense produziu Cr $\$ 35.254$ mil cruzeiros, dos quais, $86 \%$ se referiam ao que foi produzido pelas lavouras temporárias e $0,44 \%$ por lavouras permanentes. 
Ademais, a Tabela 3 a seguir indica as áreas utilizadas para a produção de culturas agrícolas com disponibilidade de informação entre 1970 e 1985, informação em que as maiores áreas para culturas temporárias e permanentes foram evidenciadas. Dessa informação se pode depreender que as culturas temporárias são aquelas com as maiores áreas produtivas, sendo a soja e o milho incluídos no agrupamento com maior área produtiva em todos os anos.

Tabela 3 - Área (ha) destinada à produção agrícola por cultura - 1970 a 2018

\begin{tabular}{l|r|r|r|r|r}
\hline \multicolumn{1}{c|}{ Cultura Agrícola } & \multicolumn{5}{|c}{ Área (ha)/Ano } \\
\hline \multicolumn{1}{c}{ Cultura Permanente } & $\mathbf{1 9 7 0}$ & $\mathbf{1 9 8 5}$ & $\mathbf{1 9 9 5}$ & $\mathbf{2 0 0 5}$ & $\mathbf{2 0 1 8}$ \\
\hline Banana & $\mathbf{1 4 8}$ & 30 & 12 & 0 & $\mathbf{2 0}$ \\
\hline Café & 90 & $\mathbf{2 5 2}$ & 0 & $\mathbf{1 6}$ & 14 \\
\hline Laranja & 16 & 59 & 10 & 0 & 0 \\
\hline Tangerina & 0 & 83 & $\mathbf{1 6}$ & 0 & 0 \\
\hline Uva & 15 & 13 & $\mathbf{1 6}$ & 0 & 5 \\
\hline
\end{tabular}

\begin{tabular}{l|r|r|r|r|r}
\hline \multicolumn{1}{c|}{ Cultura Temporária } & \multicolumn{2}{c|}{} \\
\hline Algodão em caroço & $\mathbf{1 9 . 2 8 0}$ & $\mathbf{6 . 0 2 5}$ & $\mathbf{6 . 0 0 0}$ & 10 & 0 \\
\hline Amendoim em casca & 371 & 576 & 5 & 50 & 0 \\
\hline Arroz em casca & 2.680 & 0 & 800 & 600 & 10 \\
\hline Aveia em casca & 0 & 24 & 0 & 600 & 0 \\
\hline Batata inglesa & 14 & 1 & 0 & 0 & 0 \\
\hline Cana & 46 & 18 & 0 & 0 & 50 \\
\hline Feijão em grão & $\mathbf{2 3 . 6 2 4}$ & 717 & 700 & 0 & 0 \\
\hline Fumo em folha & 0 & 39 & 1 & 0 & 0 \\
\hline Mamona & 0 & 23 & 0 & 0 & 0 \\
\hline Mandioca & 534 & 130 & 800 & 2.000 & 2.540 \\
\hline Milho em grão & $\mathbf{3 2 . 0 4 3}$ & $\mathbf{4 . 6 0 8}$ & $\mathbf{3 7 . 0 0 0}$ & $\mathbf{3 0 . 5 0 0}$ & $\mathbf{6 5 . 5 0 0}$ \\
\hline Soja & $\mathbf{2 2 . 9 0 1}$ & $\mathbf{6 1 . 6 2 1}$ & $\mathbf{6 1 . 5 0 0}$ & $\mathbf{7 2 . 2 0 0}$ & $\mathbf{7 0 . 1 0 0}$ \\
\hline Sorgo em grão & 0 & 56 & 0 & 0 & 0 \\
\hline Tomate & 0 & 144 & 0 & 0 & 6 \\
\hline Trigo & 3.044 & $\mathbf{6 7 . 7 2 6}$ & $\mathbf{3 0 . 0 0 0}$ & $\mathbf{4 0 . 0 0 0}$ & $\mathbf{5 . 0 0 0}$ \\
\hline
\end{tabular}

Fonte: Elaborado a partir de IBGE (1970b, 1985, 1995, 2005, 2018).

Mediante a redução do número de culturas produzidas com o passar dos anos, foi recorrido ao Zoneamento Ecológico-Econômico do Estado do Paraná para identificar se existem restrições de culturas produtivas para o local. O documento considera que a Zona 11 é aquela à qual o município de Assis Chateaubriand está incluído e sobre a mesma relata-se que: 
[...] não apresenta restrições significativas para a produção agrícola, devido ao predomínio de baixa fragilidade geoambiental em relação aos relevos de baixa declividade e solos bem desenvolvidos [...] apresenta potencialidade para agricultura intensiva de grãos em função da alta aptidão agrícola e crescimento da atividade agroindustrial e de equipamentos agrícolas [...] As diretrizes preferenciais vinculam-se a manutenção e melhoramento da agricultura intensiva de grãos, inclusive com desenvolvimento das técnicas da agricultura de precisão na pequena propriedade, ampliação das atividades agroindustriais e indústria de equipamentos agrícolas; expansão da avicultura e suinocultura; expansão da indústria de processamento de carnes; implementação de políticas de incentivo ao turismo em áreas específicas; e incentivo à atividades de alto valor adicionado por meio da utilização do capital humano existente (PARANÁ, 2015, p. 233).

O Zoneamento deixa claro que não se encontram restrições significativas para a região em relação à produção agrícola, pelo contrário, esta é incentivada incluindo a expansão da produção animal na região. Por outro lado, outros fatores apresentados por Ferreira (1985) podem ter influenciado os produtores em relação ao processo de tomada de decisão sobre o plantio no decorrer dos anos. A partir de 1962, o governo reduziu os financiamentos da produção cafeeira no país, iniciativa que visava incentivar a produção de outras culturas agrícolas, e, na década de 1970, facilitou as condições do crédito para a intensificação de mecanização rural, necessária a outras produções.

Em relação à produção rural observa-se, ainda, que o IBGE (1970b) disponibilizou informações que mostraram que, na década de 1970, Assis Chateaubriand apresentava uma produção agrícola diversificada e que, em parte, demandava a inserção de tecnologias rurais. Contudo, mantinha a necessidade do uso de mão de obra humana. O Censo Agropecuário indicou a produção de sete produtos de forma permanente e 37 itens de produção temporária. As culturas agrícolas que utilizavam as maiores áreas produtivas eram, pela ordem, milho, feijão e soja.

Em 2017, a pesquisa de Produção Agrícola Municipal realizada pelo IBGE, indicou a produção agrícola permanente de seis itens e produção agrícola temporária de 10 itens, sendo soja e milho, respectivamente, as principais culturas, o que se deduz do fato de terem ocupado as maiores áreas produtivas (IBGE, 2019). Dessa forma, o município reduziu a sua diversidade produtiva e ainda está mais direcionado à produção de culturas agrícolas com maior exigência de tecnologias rurais. Para Costa (2013), o município de Assis Chateaubriand foi um dos pioneiros no uso da mecanização agrícola no estado do Paraná, possibilitando, com o passar do tempo, que o panorama produtivo de 2017 estivesse consolidado. 
Em relação ao uso de tecnologias rurais, a Figura 7 mostra a valorização da inserção desses componentes para as lideranças locais, tendo em vista que um conjunto de tratores foi inserido em um dos desfiles cívicos que ocorreu na cidade, como a imagem demonstra.

Figura 7 - Trator - Tecnologia rural em desfile cívico

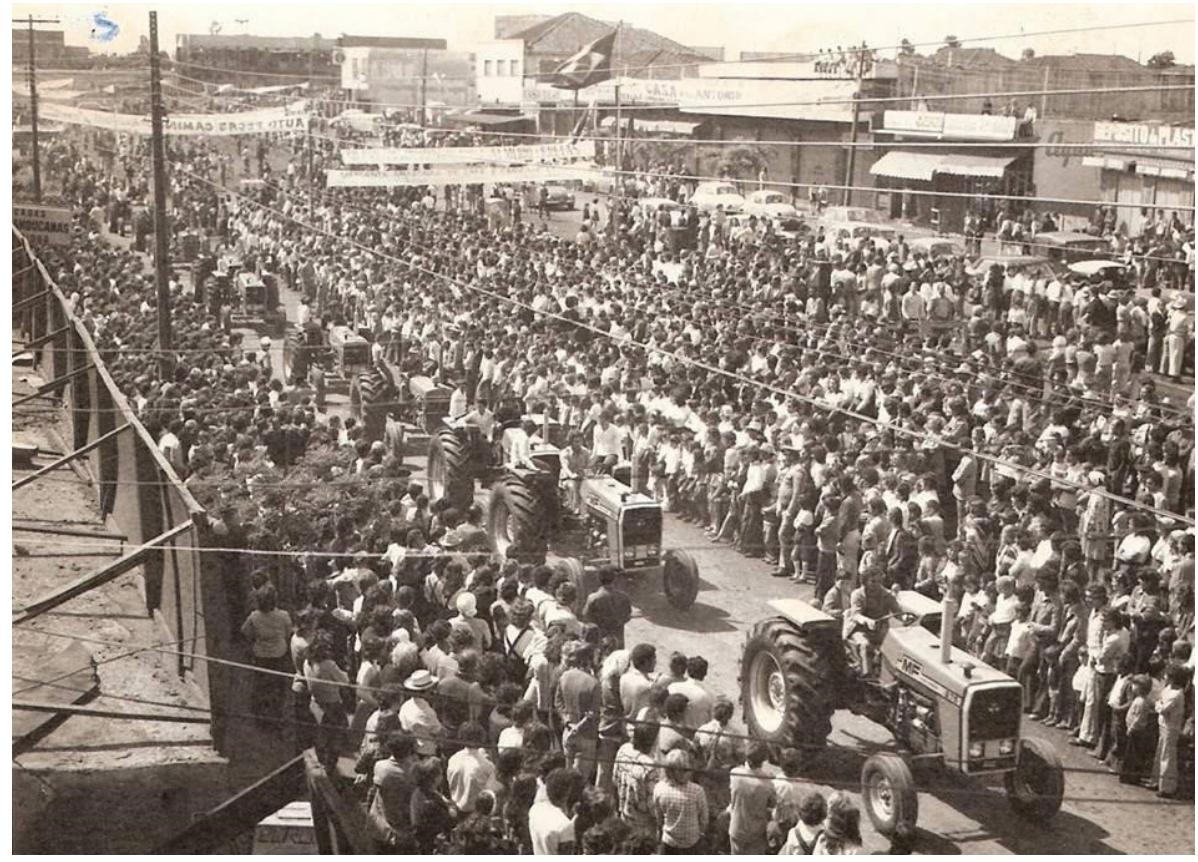

Fonte: Acervo da biblioteca municipal de Assis Chateaubriand (2018).

Também se pode observar na imagem, a aglomeração das pessoas que frequentaram esse evento. $\mathrm{O}$ ano da fotografia e sua autoria não puderam ser identificados, mas acredita-se que a fotografia tenha sido realizada entre as décadas de 1960 e 1970, por isso, o ano não foi identificado na figura. Existem registros sobre o número de tratores adquiridos por produtores no município. Observa-se que o Censo Agropecuário registrou, em 1970, a existência de 73 tratores em Assis Chateaubriand e, em 2017, esse número aumentou para 1.519 unidades (IBGE, 1970b, 2017).

Após a abordagem sobre o uso da terra, vê-se a necessidade de incluir na análise a estrutura fundiária do local e seu comportamento no decorrer dos anos. Observa-se que essa estrutura tem alterações registradas a cada Censo Agropecuário no período de 1970 a 2017. Essas alterações implicam um relevante processo de concentração de terras, tendo em vista que a redução no número de propriedade é de 82\%, comparando-se os anos de 1970 e 2017 (Tabela 4). 
Tabela 4 - Estrutura fundiária (em hectares) de Assis Chateaubriand - 1970 a 2017

\begin{tabular}{|c|c|c|c|c|c|c|}
\hline $\begin{array}{c}\text { Grupo de área - } \\
\text { Hectares }\end{array}$ & 1970 & 1985 & $1995 / 96$ & 2006 & 2017 & $\begin{array}{c}\text { Variação } \\
1970-2017(\%)\end{array}$ \\
\hline Menos de 1 & 7 & 56 & 52 & 28 & 75 & 971 \\
\hline 1 a menos de 2 & 145 & 67 & 76 & 41 & 24 & -83 \\
\hline 2 a menos de 5 & 2702 & 748 & 618 & 443 & 158 & -94 \\
\hline 5 a menos de 10 & 2617 & 848 & 651 & 508 & 180 & -93 \\
\hline 10 a menos de 20 & 2071 & 1234 & 894 & 713 & 297 & -86 \\
\hline 20 a menos de 50 & 733 & 809 & 765 & 660 & 370 & -50 \\
\hline 50 a menos de 100 & 59 & 202 & 240 & 264 & 178 & 202 \\
\hline 100 a menos de 200 & 14 & 81 & 97 & 98 & 99 & 607 \\
\hline 200 a menos de 500 & 15 & 31 & 45 & 29 & 69 & 360 \\
\hline 500 a menos de 1000 & 0 & 4 & 4 & 10 & 16 & - \\
\hline 1000 a menos de 2500 & 0 & 1 & 1 & 2 & 3 & - \\
\hline Total & 8363 & 4081 & 3443 & 2796 & 1469 & -82 \\
\hline
\end{tabular}

Fonte: Elaborado a partir do IBGE (1970b, 1985, 1996, 2006, 2017).

Dessa forma, até os anos 2000, o maior número de propriedades se encontrava sempre no mesmo grupo de área, ou seja, o agrupamento com áreas entre 2 e menos de 50 hectares de terras. Em 2017, esse agrupamento de propriedades aparece alterado para áreas com 5 e menos de 100 hectares. Outra questão a ser observada é que, com exceção do grupo com áreas menores que 1 hectare, todos os grupos com áreas de até menos de 50 hectares tiveram uma variação negativa, ou seja, redução no número de propriedades quando comparadas as situações de 1970 e de 2017. Por outro lado, os grupos com áreas maiores que 50 hectares têm crescido na variação percentual. No caso dos grupos com áreas entre 500 e menos de 1000 e com 1000 a menos de 2500 hectares não foi possível estabelecer uma variação percentual, devido ao fato de em 1970 não existirem registros de propriedades com essa extensão de terra. Porém, é visível, nos anos seguintes, o aumento no número das propriedades com essas características (Tabela 4).

A respeito dessa situação, é importante apontar que o tipo de estrutura fundiária é um componente que se destaca no estudo das questões relacionadas ao crescimento econômico da localidade para a caracterização das políticas públicas agrárias (RADA; FUGLIE, 2018) e para indicar quem e quantos indivíduos podem ser beneficiados por ações governamentais, conforme o enfoque dado à ação pública (THIESENHUSEN; MELMED-SANJAK, 1990). Além disso, e ainda 
conforme esses autores, na estrutura fundiária de uma determinada localidade são reveladas as possíveis disparidades de renda ocorridas no espaço rural.

Assim sendo, são consideradas estruturas agrárias desiguais aquelas que apresentam a coexistência de produtores com concentração de terras em grandes áreas paralelamente à existência de pequenas propriedades (JANVRY, 1981). Os dados apresentados indicam que o município de Assis Chateaubriand possui uma estrutura agrária que, a cada registro oficial de informações, se torna mais desigual. Nesses casos, a desigualdade está além das questões econômicas, sendo refletida na grande discrepância de poder desses diferentes atores rurais. Segundo Janvry (1981), o acúmulo de poder dos latifundiários sobre a formação da política agrária garante a permanência da desigualdade na estrutura.

\section{CONSIDERAÇÕES FINAIS}

Ao longo deste estudo, buscou-se responder ao questionamento: que alterações ocorreram com a ocupação do solo e da paisagem do município de Assis Chateaubriand no decorrer de sua história? Aponta-se que foi possível perceber que o município sofreu alterações significativas na substituição da vegetação natural por alguns usos intencionais da terra, antes da década de 1985, tendo em vista que a vegetação natural (floresta) apresenta baixo percentual na configuração do uso da terra, que foi observado no mesmo ano (1985 - 2\%), em que essa configuração de uso, apresentou predominância, desde meados da década de 1980, destacando-se a agropecuária, com ênfase na agricultura. Posteriormente a essas transformações iniciais, principalmente a partir do desmatamento da área, aponta-se que não ocorreram muitas transformações significativas no uso da terra do município durante o período analisado (1985 a 2017). Manteve-se o perfil de uso da terra municipal, tornando esse perfil ainda mais restritivo a uma única categoria, quando se observa que o percentual destinado à agricultura em 2017 é maior que o observado em 1985.

Pode-se identificar também, que dentre as alterações verificadas, ocorreu a substituição da produção de culturas permanentes por temporárias ou por reflorestamentos ao longo dos anos, como visto nos resultados da pesquisa. Isso foi possível ser verificado por meio dos dados históricos utilizados e uso de imagens que auxiliaram na confirmação dessas características do uso da terra na atualidade, podendo ser percebido que o padrão de uso agrícola se manteve. Em relação à paisagem, foi possível concluir que esta sofreu importantes modificações principalmente em razão do processo de substituição 
da vegetação natural do território por culturas tecnicamente mais avançadas commodities, apresentando-se na atualidade como uma paisagem homogênea e que retrata o uso da terra do município.

Além disso, em relação à população, verificou-se que o processo de colonização do município contou com a propaganda de possibilidade de prosperidade econômica na localidade para as pessoas. Essa propaganda estava relacionada aos recursos naturais disponíveis, como por exemplo as terras férteis da área. As migrações que ocorreram, possibilitaram que o município conseguisse acumular uma população maior que 70.000 habitantes em poucos anos. Como essa atração estava vinculada ao processo econômico e produtivo local, ou seja, à produção agrícola em um período no qual o país passava por transformações no seu modelo produtivo, o município, ao aderir à modernidade rural nacional, sofreu com a ocorrência de fluxos de emigração. Um processo de diversificação produtiva poderia ter contribuído para que parte dessa população permanecesse no município, colaborando com o seu desenvolvimento.

Assim, a inserção expressiva de tecnologias rurais e o plantio de determinadas culturas alimentares, por exemplo, reduziram a necessidade do uso da mão de obra e exigiam que os produtores rurais tivessem um volume maior de capital para investir nos equipamentos necessários à produção para permanecerem em suas atividades. Esse processo de modernização utilizou medidas de transformação do modelo produtivo utilizado no período, de tal modo que não havia mais a necessidade do uso de mão de obra extensiva. Resultando em um relevante processo de emigração dessas pessoas para outras localidades, que atingiu um volume expressivo de até 30\% da população no decorrer de uma década, período de 1970 a 1980.

Assim, esse processo de saída das pessoas do município influenciou a estrutura fundiária local, de modo que é possível identificar a ocorrência de uma estrutura fundiária mais heterogênea, com características de concentração de terras no período sob análise, fato fundamentalmente vinculado à transformação produtiva ocorrida no campo que levou ao deslocamento das pessoas do rural para outros lugares. A concentração de terras possibilitou que, em 1985, fossem identificadas propriedades com mais de 1.000 hectares de área. Sendo que propriedades com esse porte não existiam na área na década de 1970, momento em que havia no município uma maior quantidade de pequenas e médias propriedades. Por meio dos apontamentos realizados ao longo do estudo, acredita-se que o objetivo delimitado foi alcançado. Pesquisas futuras podem ser direcionadas a outros municípios da região Oeste do Paraná, para identificar se essas mudanças identificadas no município de Assis Chateaubriand são semelhantes em outras localidades. 


\section{REFERÊNCIAS}

BAJA, S.; CHAPMAN, D. M.; DRAGOVICH, D. A conceptual model for defining and assessing land management units using a fuzzy modeling approach in GIS environment. Environmental Management, [s. l.], v. 29, n. 5, p. 647661, 2002.

BESTELMEYER, B. T.; HERRICK, J. E.; BROWN, J. R.; TRUJILLO, D. A.; HAVSTAD, K. M. Land management in the American southwest: a state-and-transition approach to ecosystem complexity. Environmental Management, [s. l.], v. 34, n. 1, p. 38-51, 2004.

BORITZA, R. Assis Chateaubriand: história e memória. Revista Espaço Plural, Marechal Cândido Rondon, v. 12, n. 25, p. 102-118, 2011.

CAMPOS, S.; NARDINI, R. C.; BARROS, Z. X.; CARDOSO, L. G. Sistema de informações geográficas aplicado à espacialização da capacidade de uso da terra. Pesquisa Agropecuária Tropical, Goiânia, v. 40, n. 2, p. 174-179, 2010.

COSTA, F. R. A noção de municípios periféricos: contradições e desigualdades no estado do Paraná. 2013. 215 p. Tese (Doutorado em Geografia) - Programa de Pós-Graduação em Geografia, Universidade Estadual de Maringá, Maringá, 2013.

CRESTANI, L. A. Narrativas da diferença: memórias dos conflitos agrários na região Oeste do Paraná (1950/80). In: COLÓQUIO INTERNACIONAL CULTURA E MEMÓRIA SOCIAL, 5., 2011, Paraná. Anais [...]. Paraná: Unioeste, 2011. p. 1-16.

CUNHA, C. M. L.; PINTON, L. G. Avaliação da capacidade de uso da terra da bacia do Córrego do Cavalheiro - Analândia, SP. Geociências, São Paulo, v. 31, n. 3, p. 459-471, 2012.

EMBRAPA. Sistema brasileiro de classificação de solos. 3. ed. Brasília, DF: Embrapa, 2013. 353 p.

FERREIRA, Y. N. Industrialização e urbanização no Paraná. Geografia, Londrina, v. 3, n. 3, p. 113-128, 1985.

FLICK, U. Introdução à pesquisa qualitativa. 3.ed. Porto Alegre: Bookman, 2009a.

FLICK, U. Qualidade na pesquisa qualitativa. Porto Alegre: Bookman, 2009b.

FLICK, U. Introdução à metodologia de pesquisa. Porto Alegre: Penso, 2013. 


\section{GOOGLE EARTH PRO. Imagens de satélite do município de Assis}

Chateaubriand. Versão 7.3.2 [California]: Google, 2018.

IBGE. Censo Demográfico 1970. IBGE, Rio de Janeiro, 1970a. Disponível em: https://sidra.ibge.gov.br/pesquisa/censo-demografico/series-temporais/seriestemporais/. Acesso em: 30 out. 2019.

IBGE. Censo Agropecuário 1970. Rio de Janeiro: IBGE, $1970 \mathrm{~b}$.

IBGE. Censo Demográfico 1980. IBGE, Rio de Janeiro, 1980. Disponível em: https://sidra.ibge.gov.br/pesquisa/censo-demografico/series-temporais/seriestemporais/. Acesso em: 05 nov. 2019.

IBGE. Censo Agropecuário 1985. IBGE, Rio de Janeiro, 1985. Disponível em: https://sidra.ibge.gov.br/pesquisa/censo-agropecuario/series-temporais. Acesso em: 30 out. 2019.

IBGE. Censo Demográfico 1991. IBGE, Rio de Janeiro, 1991. Disponível em: https://sidra.ibge.gov.br/pesquisa/censo-demografico/series-temporais/seriestemporais/. Acesso em: 05 nov. 2019.

IBGE. Censo Agropecuário 1995. Rio de Janeiro: IBGE, 1995.

IBGE. Censo Agropecuário 1996. IBGE, Rio de Janeiro, 1996. Disponível em: https://sidra.ibge.gov.br/pesquisa/censo-agropecuario/series-temporais. Acesso em: 30 out. 2019.

IBGE. Censo Demográfico 2000. IBGE, Rio de Janeiro, 2000. Disponível em: https://sidra.ibge.gov.br/pesquisa/censo-demografico/series-temporais/seriestemporais/. Acesso em: 5 nov. 2019.

IBGE. Censo Agropecuário 2005. IBGE, Rio de Janeiro, 2005. Disponível em: https://sidra.ibge.gov.br/pesquisa/censo-agropecuario/series-temporais. Acesso em: 30 out. 2019.

IBGE. Censo Agropecuário 2006. IBGE, Rio de Janeiro, 2006. Disponível em: https://sidra.ibge.gov.br/pesquisa/censo-agropecuario/series-temporais. Acesso em: 30 out. 2019.

IBGE. Censo Demográfico 2010. IBGE, Rio de Janeiro, 2010. Disponível em: https://sidra.ibge.gov.br/pesquisa/censo-demografico/series-temporais/seriestemporais/. Acesso em: 05 nov. 2019.

IBGE. Malhas Digitais. IBGE, Rio de Janeiro, 2015. Disponível em: mapas. ibge.gov.br. Acesso em: 18 out. 2019. 
IBGE. Censo Agropecuário 2017. IBGE, Rio de Janeiro, 2017. Disponível em: https://sidra.ibge.gov.br/pesquisa/censo-agropecuario/censoagropecuario-2017. Acesso em: 10 dez. 2019.

IBGE. Pesquisa Pecuária Municipal - PPM. IBGE, Rio de Janeiro, 2018. Disponível em: https://sidra.ibge.gov.br/pesquisa/ppm/quadros/brasil/2017. Acesso em: 04 nov. 2018.

IBGE. Série Temporais do Censo Demográfico. IBGE, Rio de Janeiro, 2019. Disponível em: https://sidra.ibge.gov.br/pesquisa/censo-demografico/seriestemporais/series-temporais/. Acesso: 04 dez. 2019.

IBGE. Cidades. IBGE, Rio de Janeiro, 2020. Disponível em: https://cidades. ibge.gov.br/. Acesso em: 24 abr. 2020.

IPARDES. Grau de Urbanização. Ipardes, Curitiba, 2019. Disponível em: http://www.ipardes.pr.gov.br/imp/index.php. Acesso em: 12 dez. 2019.

JANVRY, A. The agrarian question and reformism in Latin America. Baltimore: Johns Hopkins University Press, 1981.

LIMA, M. S. Morfologia urbana e qualidade de vida na cidade de Assis Chateaubriand/PR. 2004. 175 f. Dissertação (Mestrado em Geografia) Departamento de Geografia, Programa de Pós-Graduação em Geografia, Universidade Estadual de Maringá. Maringá, 2004.

MAIMONE, G. D.; GRACIOSO, L. S. Representação temática de imagens: perspectivas metodológicas. Informação \& Informação, Londrina, v. 12, n. 1, p. 130-141, 2007.

MANINI, M. P. Análise documentária de imagens. Informação \& Sociedade, João Pessoa, v. 11, n. 1, 2001.

MAPBIOMAS. Estatísticas. MapBiomas Brasil, [s. l.], 2019. Disponível em: http://mapbiomas.org/stats. Acesso em: 17 nov. 2019.

MARQUES, M. Narrativas orais de moradores do distrito de Bragantina, município de Assis Chateaubriand, Oeste do Paraná. História Oral, São Paulo, v. 20, n. 1, p. 169-190, 2017.

MERTZ, O.; MERENS, C. F. Land sparing and Land sharing policies in developing countries drivers and linkages to scientific debates. World Development, [s. l.], n. 98, p. 523-535, 2017. 
NASCIMENTO, V. M.; VAN BELLEN, H.M.; BORGERT, A.; NASCIMENTO, M. ICMS - Ecológico: análise dos aspectos financeiros e de sustentabilidade nos municípios do estado do Paraná. Revista Capital Científico, Guarapuava, v. 9, n. 2, p. 71-82, 2011.

PANOFSKY,E. Significado nas artes visuais. 2. ed. São Paulo: Perspectiva, 1979.

PARANÁ. Zoneamento Ecológico-Econômico do Estado do Paraná. Curitiba: Secretaria de Meio Ambiente, 2015.

RADA, N. E.; FUGLIE, K. O. New perspectives on farm size and productivity. Food Policy, [s. l.], v. 84, p. 147-152, Apr. 2018.

RIPPEL, R. Migração e desenvolvimento econômico no Oeste do Paraná: uma análise de 1950 a 2000. 2005. 261 p. Tese (Doutorado em Demografia) - Programa de Pós-Graduação em Demografia, Universidade Estadual de Campinas, Campinas, 2005.

RODRIGUES, C. R. Análise e tematização da imagem fotográfica. Ciência da Informação, Brasília, v. 36, n. 3, p. 67-76, set./dez. 2007.

SANTOS, L. P. FERRERA DE LIMA, J. Desenvolvimento Econômico Local Em Assis Chateaubriand-Pr. Desenvolvimento Regional em Debate, Canoinhas, v. 5, n. 1, p. 180-200, 2015.

SERRA, A. B. Indicadores de sustentabilidade do solo em sistemas alternativos ao uso do fogo, baseados nos princípios da agroecologia, desenvolvidos por agricultores familiares na região da Rodovia Transamazônica. 2005. 84 f. Dissertação (Mestrado em Agriculturas Familiares e Desenvolvimento Sustentável) - Programa de Pós-Graduação em Agriculturas Amazônicas, Universidade Federal do Pará, Belém, 2005.

SERRA, E. Conflitos rurais no Paraná: como foi que tudo começou. Boletim de Geografia, Maringá, v. 28, n. 1, p. 75-89, 2010.

SOUTO MAIOR, L. História do município de Assis Chateaubriand: o encontro das correntes migratórias na última fronteira agrícola do estado do Paraná. Maringá, PR: Clichetec, 1996.

SPALDING, A. K. Exploring the evolution of land tenure and land use change in Panama: linking land policy with development outcomes. Land Use Policy, [s.l.], n. 61, p. 543-552, 2017.

SWAIN, T. N. Fronteiras do Paraná: da colonização à migração. Curitiba: Ipardes, 1992. 
THIESENHUSEN, W.C.; MELMED-SANJAK, J. Brazil's agrarian structure: changes from 1970 through 1980. World Development, [s. l.], v. 18, n. 3, p. 393-415, 1990.

ZHANG, Q.; YUE, D.; FANG, M. et al. Study on sustainability of land resources in Dengkou County based on emergy analysis. Journal of Cleaner Production, [s. l.], n. 171, p. 580-591, 2018. 